\title{
Die rol van taalleeronderrig in Afrikaanse woordeboekwerkboeke
}

\author{
Michele F. van der Merwe, Departement Kurrikulumstudies: Afrikaans, \\ Fakulteit Opvoedkunde, Universiteit Stellenbosch, Stellenbosch \\ (michelevdm@sun.ac.za)
}

Opsomming: Hierdie artikel beskou die rol van woordeboekwerkboeke in die vaardigheidsopvoeding van gebruikers in Afrikaans. Woordeboekwerkboeke word gewoonlik op 'n spesifieke skool- of aanleerderwoordeboek gerig en sluit sodoende by die opvoedkundige leksikografie aan. Die hoofdoel van werkboeke behoort dus 'n opvoedkundige een te wees. Alhoewel die opvoedkundige leksikografie meer belangstelling in Suid-Afrika wek, word weinig aandag gegee aan die belangrike rol van woordeboekwerkboeke. Woordeboekwerkboeke behoort baie gebruikersgerig te wees, aangesien dit vir spesifieke teikengebruikers saam met die gebruik van 'n spesifieke woordeboek opgestel word. Die doel van werkboeke word in hierdie artikel geïdentifiseer deur verskeie werkboeke in die Afrikaanse konteks te analiseer. By nadere ondersoek blyk dit dat werkboeke diverse doelstellings het en ook diverse inhoude bevat. Werkboeke is daarop gemik om teikengebruikers meer woordeboekgeletterd te maak, d.w.s. om woordeboeke sinvol te kan gebruik en inligting daaruit suksesvol te ontsluit. Die wyse waarop inligting in werkboeke aangebied en dus oorgedra word, reflekteer sekere onderrigbenaderings in taal en hoe dit gestalte kan vind in werkboeke. Wanneer 'n onderrigbenadering suksesvol toegepas word, is die verwagting dat gebruikers se vaardighede sal verbeter. Gevolglik word daar verwys na die ontwikkeling van sekere vaardighede.

Sleutelwoorde: AFRIKAANSE OPVOEDKUNDIGE LEKSIKOGRAFIE, SKOOLWOORDEBOEKE, AANLEERDERSWOORDEBOEKE, WOORDEBOEKWERKBOEKE, TAALLEERONDERRIG, TAALLEERONDERRIGBENADERINGS, TEKSGEBASEERDE BENADERING, KOMMUNIKATIEWE BENADERING, LEERDERGERIGTE ONDERRIGBENADERING, INDUKTIEWE ONDERRIGMETODE, KONSTRUKTIVISME, ONDERRIGLEERAKTIWITEITE, LEERDERS SE WOORDEBOEKVAARDIGHEDE, ONDERWYSER, LEKSIKOGRAAF, UITGEWER

\begin{abstract}
Criteria for Dictionary Workbooks in Afrikaans. This article reflects on the role of dictionary workbooks in the skills training of users in Afrikaans. Dictionary workbooks are usually directed at a specific school or learners' dictionary and in this way links up with pedagogical lexicography. The main purpose of workbooks should thus be an educational one. Although pedagogical lexicography is generating more interest in South Africa, very little attention has been paid to the important role of dictionary workbooks. Dictionary workbooks should be very user oriented, since they are compiled for specific target users using a specific dictionary. The purpose of dictionary workbooks is identified in this article by analysing various workbooks in the Afrikaans context. On closer investigation it was found that workbooks could have diverse purposes and could contain diverse contents. Workbooks are aimed at making target users more dictionary literate, i.e. to be able to use dictionaries meaningfully and to unlock information suc-
\end{abstract}

Lexikos 23 (AFRILEX-reeks/series 23: 2013): 426-439 
cessfully. The manner, in which information in workbooks is presented and thus conveyed, reflects certain educational approaches in language and how they can find shape in workbooks. When an educational approach is successfully applied, the expectations are that user skills should be improved. Hence reference is also made to the development of certain skills.

Keywords: AFRIKAANS PEDAGOGICAL LEXICOGRAPHY, SCHOOL DICTIONARIES, LEARNER'S DICTIONARIES, DICTIONARY WORKBOOKS, LANGUAGE TEACHING, LANGUAGE TEACHING APPROACHES, TEXT-BASED APPROACH, COMMUNICATIVE APPROACH, LEARNER-CENTRED TEACHING APPROACH, INDUCTIVE TEACHING METHOD, CONSTRUCTIVISM, LANGUAGE TEACHING ACTIVITIES, DICTIONARY SKILLS OF LEARNERS, TEACHER, LEXICOGRAPHER, PUBLISHER

\section{Inleiding}

Opvoedkundige leksikografie (met verwysing na skool- en aanleerderwoordeboeke) geniet die afgelope tyd meer belangstelling in Suid-Afrika, soos geillustreer deur onlangse artikels oor die onderwerp. Vergelyk onder andere Tarp en Gouws (2004), Gouws (2006), Gouws en Tarp (2008) en Beyer (2010) in hierdie verband. Daar is egter weinig aandag aan die rol van woordeboekwerkboeke en die inhoud daarvan aandag gegee. Vergelyk Van der Merwe (2013). Woordeboekwerkboeke het ' $n$ groot rol te speel in sowel skole as in die samelewing, aangesien dit die probleemoplossende potensiaal van woordeboeke belig.

In hierdie artikel word die bydrae van werkboeke tot die vaardigheidsopvoeding van woordeboekgebruikers ondersoek. Die vraag word gevra wat die doel van woordeboekwerkboeke is en of die werkboeke slaag in die doel wat gestel word. Die rol van woordeboekwerkboeke in die taalonderrigsituasie word beskryf. Benaderings tot taalonderrig in skole word verduidelik en ' $n$ spesifieke metode vir taalonderrig met behulp van werkboeke word voorgestel. Watter vaardighede word aangeleer deur die gebruik van sulke werkboeke en watter vaardighede behoort aangeleer te word? Hoe moet die inligting aangebied en oorgedra word? Die artikel word vanuit die oogpunt van 'n kurrikulumstudie benader en probeer om 'n bydrae op teoretiese gebied te maak.

\section{Die doel van woordeboekwerkboeke}

Volgens Chi (1998: 565) geniet naslaanwerke hoë status in die Chinese kultuur, aangesien dit beskou word as "'n onderwyser wat nie kan praat nie". Woordeboeke word naas die onderwyser in die klas as die betroubaarste alternatief vir leer beskou. Chi wys daarop dat moderne leksikograwe en uitgewers ' $n$ verskeidenheid tegnieke of maniere toepas om te verseker dat naslaanwerke en spesifiek woordeboeke, toegankliker, deursigtiger en makliker is om te verstaan as in die verlede.

Woordeboekwerkboeke word ook ontwerp om gebruikers te leer om woor- 
deboeke te gebruik met behulp van verskillende soorte oefeninge. 'n Verskeidenheid gegradeerde oefeninge word aangebied om gebruikers van hulp te wees, ook in die klaskamer.

Stark (1990: 30) beskou 'n woordeboekwerkboek as 'n tekstipe met unieke status. Dit is ' $n$ teks georiënteer ten opsigte van gebruikers om hulle te help om optimale voordeel uit 'n spesifieke naslaanwerk, naamlik 'n woordeboek te kan trek.

Die Macmillan English Dictionary for Advanced Learners Workbook se doel word duidelik in die voorwoord aan die gebruiker gestel, naamlik: "This workbook will help you to get the best out of your dictionary, and by working through these activities you will be able to find words quickly, learn how to find pronunciation and stress, use grammatical information, find and explore meanings, learn which words are used together and choose the right word for the context. Explanations and examples are followed by activities to practise your dictionary and language skills." Die volgende motivering word ook aan gebruikers gestel: "Being able to use a dictionary well is a great pleasure and will bring independence and confidence to your language studies."

Volgens die Nuwe Woordeboek sonder grense Werkboek (WSGW) sal die werkboek "leerders help om die vaardighede aan te leer om Nuwe Woordeboek sonder grense doeltreffend te gebruik". Leerders sal volgens die aannames op die agterblad van die werkboek gelei word om "hul woordeskat te verbreed, alfabetiese volgorde te leer ken, die struktuur van woordeboeke te verstaan en daarmee te werk, asook om woordsoorte op 'n eenvoudige vlak te onderskei en te gebruik".

Die Oxford Tweetalige Werkboek (OTW) beloof op die agterblad dat die werkboek "maklik is om te gebruik en vol nuttige aktiwiteite is. Dit help leerders om algemene struikelblokke te oorkom, bv. om die regte vertaling te kies. Dit bou leerders se woordeskat uit met behulp van oefeninge met voorvoegsels, meervoude, verkleinwoorde, woordsoorte, ens. Die OTW dien as gids vir leerders om die meeste uit hulle woordeboeke te kry, bv. trappe van vergelyking, onreëlmatige werkwoorde, hulp met die skryf van 'n e-pos of brief. Dit sluit antwoorde vir al die aktiwiteite, asook bondige aantekeninge vir onderwysers of ouers op elke bladsy in." Beide werkboeke se fokus is dus op taal- en woordeboekonderrig.

Volgens Pharos Leerderboek by die Skoolwoordeboek (PLS) (voorwoord, p. vi) "fokus die aktiwiteite daarop om woordeboekvaardighede by gebruikers in te skerp. Hulle word ook toegerus met die nodige vaardighede om suksesvolle briewe te skryf en projekte met gemak aan te pak." Die term woordeboekvaardighede word nie verduidelik nie. Die opsteller van die werkboek verwys ook na die sogenaamde buitetekste, wat nie noodwendig deel uitmaak van die opdrag van 'n skoolwoordeboek nie en leerders word vaardighede daaroor aangeleer, bv. die skryf van briewe. Die fokus is op die aanleer van woordeboekvaardighede en die ontwikkeling van skryfvaardighede vir transaksionele tekste.

In die Pharos Leerderboek by die Aanleerderswoordeboek (PLA) (voorwoord) 
word die doel van die werkboek soos volg geformuleer: "Die aktiwiteite is toegespits op taalaspekte soos woordsoorte, woordfamilies en woordgroepe. Die blokraaisels toets leerders se vaardigheid met onder meer leestekengebruik, formele en informele taalgebruik en meervoudsvorme." 'n Belofte word ook gemaak dat "wanneer gebruikers die aktiwiteite in hierdie boek baasgeraak het, sal hulle die nodige vaardighede hê om met gemak enige woordeboek met vrug te gebruik". Die fokus is op ontwikkeling van taal- en woordeboekvaardighede. Dit word ook vermeld dat leerders die aktiwiteite tuis of in die klas kan doen.

Kenmerkend van Pharos se boeke is dat dit "leerderboeke" genoem word en nie "werkboeke" soos die ander uitgewers s'n nie. Met die leerdergerigte titels word die fokus volledig op die (skool)leerder geplaas in ooreenstemming met die neiging van die gebruikersperspektief waarvolgens leksikografiese produkte met 'n spesifieke teikengebruiker in gedagte opgestel word.

Ten opsigte van die HAT Aktiwiteite en Speletjies by die Afrikaanse Skoolwoordeboek en Afrikaanse Sakwoordeboek (HATS) word verduidelik dat "die aktiwiteite en speletjies geskryf is om gebruikers met die HAT Afrikaanse Skoolwoordeboek vertroud te maak. Werkblaaie mag in die klas gebruik word om leerders speelspeel inligting uit woordeboeke te leer ontsluit". Opvoedkundige inligting word dus aangebied vanuit die perspektief om die leerervaring genotvol te maak.

Werkboeke is afgestem op doelwitte om teikengebruikers op te lei in vaardighede om inligting in woordeboeke suksesvol te ontsluit. Die fokus is op die verbetering van die taal- en woordeboekvaardighede van leerders. Woordeboekvaardighede verwys onder meer na kennis van die alfabetiese struktuur, kennis van woordeboekstrukture, byvoorbeeld die makro- en mikrostruktuur van woordeboeke, asook die verstaan van die funksies van 'n woordeboek, byvoorbeeld vertaling van woorde. Die verbetering van die genoemde vaardighede lei daartoe om leerders sogenaamd "woordeboekgeletterd" te maak, wat 'n beduidende rol kan speel in die skep van 'n woordeboekkultuur in skole en die samelewing. Die term woordeboekgeletterd verwys na die vermoë van 'n persoon wat oor kennis beskik om 'n woordeboek sinvol te gebruik en inligting daaruit suksesvol te ontsluit. So 'n persoon moet dus oor kennis van die alfabetiese struktuur, die woordeboekstrukture en -funksies beskik.

Beyer (2010: 60) verwys na die onderrigleersituasie waar woordeboekgebruik op die een of ander manier deur die onderwyser gestimuleer word. Een van die maniere (Beyer 2010: 60) kan wees die aanbied van onderrig in woordeboekgebruik deur die onderwyser en die praktiese toepassing daarvan met behulp van woordeboekwerkboeke.

\section{Benaderings tot taalleeronderrig}

Die opvoedkundige leksikografie het skoolwoordeboeke en aanleerderwoordeboeke in bestek. Daar word in hierdie artikel na werkboeke van skoolwoorde- 
boeke, byvoorbeeld HATS, PLS en OTW en aanleerderwoordeboeke, byvoorbeeld PLA en WSG verwys. In die vorige afdeling is die doel van werkboeke beskryf en die gemeenskaplike doelwitte wat deur talle opstellers van werkboeke uiteengesit is, is die onderrig van taalvaardighede. Dit is dus belangrik vir werkboekopstellers om kennis te neem van die Department van Onderwys se benadering ten opsigte van taalleeronderig vir huistaal, addisionele taal en tweede addisionele taal.

Volgens die Kurrikulum en Assesseringsbeleidverklaring (KABV) vir Afrikaans as huistaal behoort die aspekte van taalstruktuur en/of kennis en begrip van die taal as interafhanklik van al die ander taalvaardighede beskou te word en moet dit hoofsaaklik kommunikatief en geïntegreerd in natuurlike en aktuele gebruiksverbande onderrig word.

Taalleer behoort informeel in noue korrelasie met al die fasette van die onderrig van die huistaal te staan en leerders behoort ' $n$ toepaslike kennis van en insig in die betrokke inhoude te hê en behoort in staat te wees om hierdie kennis en begrip effektief in ' $n$ verskeidenheid situasies te gebruik.

Die KABV vir Afrikaans as huistaal en addisionele taal stel dit duidelik dat die benadering tot taalleeronderrig "teksgebaseerd, kommunikatief, geïntegreerd" asook "proses-georiënteerd" moet wees.

Die teksgebaseerde en kommunikatiewe benaderings is beide afhanklik van die voortdurende gebruik en produsering van tekste. 'n Teksgebaseerde benadering stel leerders in staat om vaardige, vrymoedige en kritiese lesers en skrywers (en ontwerpers) van tekste te word. Dit sluit die luister en kyk na, en die lees en ontleding van tekste in om te verstaan hoe dit saamgestel is en watter effek dit het. ' $n$ Woordeboekartikel kan as 'n teks beskou word. Deur hierdie kritiese interaksie ontwikkel leerders die vermoë om tekste te evalueer. Die hoofbron van inhoud en konteks vir die kommunikatiewe, geïntegreerde leer en onderrig van taal is outentieke tekste. Die teksgebaseerde benadering sluit ook die produsering van verskillende tekste vir spesifieke doelstellings en teikengroepe in. 'n Begrip van die manier waarop tekste saamgestel word, rugsteun hierdie benadering.

\section{'n Leerdergerigte onderrigbenadering}

Die KABV gee ook bepaalde wenke oor hoe die onderrig benader behoort te word. Taal kom voor waar mense met mekaar verkeer en met mekaar wil kommunikeer. Betekenis staan daarom sentraal in enige kommunikasie-gebeure. Maniere waarop mense betekenis skep, asook die effektiewe kommunikasie van betekenis, behoort dus die fokus van taalonderrig te wees. Die bevordering van taalgebruiksvaardighede is gevolglik belangriker as blote kennis van taalstrukture (taalleer).

Taal bestaan nie los van die mens nie en kan dus nie as ' $n$ afgebakende lys inhoude bestudeer word nie. Die interaktiewe en sosiale aard van taal beïnvloed die onderrigbenadering, onder meer ten opsigte van metodiek, evalue- 
ring en handboekgebruik. Combrink et al. (1997: 6) beskryf dié benadering as sosiale konstruktivisme. Volgens die interaktiewe benadering skep mense taalkennis en taalprodukte in interaksie met ander mense, met ander woorde, kennis met 'n sosiale basis. Tipiese handelinge in 'n leerdergerigte klaskamer is gesprekke, spontane redenering, gesamentlike probleemoplossing en refleksie. 'n Leerdergerigte benadering (Combrink et al. 1997: 6) beteken dat leerders nie net passiewe ontvangers van taal is nie, maar ook skeppende gebruikers van taal. Kennis van taal is belangrik, asook die genot- en betekenisvolle gebruik daarvan en die ontwikkeling van interaktiewe vaardighede.

\section{Hoe vind dié onderrigbenaderings gestalte in werkboeke?}

Leerdergerigte onderrigbenaderings vind op verskeie maniere plaas in Afrikaanse werkboeke. Aangesien woordeboekartikels as tekstipe beskou word, word dit in werkboeke verskaf en vrae word daaroor aan die leerders gestel. Verskeie werkboeke maak van die teksgebaseerde benadering gebruik.

OTSW gebruik byvoorbeeld die artikel snaaks (ook verskaf in die werkboek) in teksgebaseerde aktiwiteite onder die hofie: "Hoe om inskrywings te verstaan." Sien voorbeeld 1 in dié verband.

1. Lees die hele inskrywing vir die woord snaaks en beantwoord dan die vrae.

(a) Skryf die eerste twee betekenisse van snaaks neer.

1

2

(b) Skryf die Engelse vertaling van snaaks in elk van die volgende sinne.

\begin{tabular}{|l|l|}
\hline & Engels \\
\hline Sy grappe is altyd baie snaaks. & 1. \\
\hline $\begin{array}{l}\text { Hy was snaaks genoeg nie vies vir } \\
\text { my nie. }\end{array}$ & 2. \\
\hline
\end{tabular}

\section{Voorbeeld 1}

Twee vrae word gevra, naamlik die eerste twee polisemiese onderskeidings van die woord moet neergeskryf word, asook die Engelse vertaling moet verskaf word. Met die vraag kan 'n algemene fout, naamlik dat leerders die eerste polisemiese onderskeiding van 'n woord as korrekte antwoord kies, voorkom word. Die vraag dien as voorbereiding vir die volgende moeiliker vraag by die artikel van maar. Leerders moet verder as die eerste vertaling, naamlik but, lees en tot die gevolgtrekking kom dat even though ook 'n vertaling van die woord kan wees. Met verwysing na Bloom se taksonomie vir die evaluering van kognitiewe ontwikkeling (Combrink et al. 1997: 18, 19) word kennis en 
begrip van die leerder gevra. 'n Hoërvlakvraag, naamlik toepassing, word gevra waar leerders die voegwoord maar moet gebruik om twee verskafte sinne te verbind. Hier handel dit oor sintaktiese orde, aangesien maar 'n neweskikker is en onafhanklike woordorde teweegbring.

WSG bevat ' $n$ hele aantal voorbeelde waar die teksgebaseerde benadering gebruik word. Vergelyk die aktiwiteite rakende woorde soos stad (mediostrukturele inligting), polisie (uitspraakinligting), boek (grammatiese inligting), tyd (betekenisinligting), bly (semantiese betrekkinge). Die artikel hak (polisemiese onderskeidinge) kan ter voorbeeld gebruik word. Die artikel word verskaf en 'n opdrag daaroor word gegee. Dit lui soos volg: "Sommige woorde het meer as een betekenis. Die betekenisse word met syfers aangedui, byvoorbeeld 1 en 2 . Kyk na die voorbeeld van die inskrywing in Nuwe Woordeboek sonder grense. Soek die woorde in Nuwe Woordeboek sonder grense op. Lees hul definisies en voorbeeldsinne. Besluit dan watter Engelse betekenis die beste by watter definisie pas. Skryf die nommer in die blokkie."

Aangesien WSGW op aanleerders gerig is, word daar telkens net een inligtingskategorie op 'n slag behandel. Dit pas by die gebruikers se vermoëns en vaslegging vind deur die inoefen van die konsep plaas. Dit is didakties suksesvol. Die teksgebaseerde benadering is goed om te gebruik, aangesien die woordeboekartikel in die werkboek herhaal word en die leerders word dus in kontak met die woordeboek gebring.

MacMillan maak uitstekend van die teksgebaseerde benadering gebruik. ' $n$ Teks, bv. 'n artikel of storie word verskaf en relevante vrae word gevra wat tot woordeboekgebruik oor die betrokke teks lei. Sodoende kan die gebruiker die voordeel van woordeboekgebruik ervaar. Dit lei tot WST-woordeboekondersteunde taalonderrig.

Volgens die KABV behels die kommunikatiewe benadering dat leerders baie en ryke blootstelling aan die teikentaal moet kry. Om dit te bereik, moet leerders vele geleenthede gebied word om taal te gebruik en te oefen. WSG maak uitstekend van dié benadering gebruik deur 'n Afrikaanse liedjie se woorde (met musiek) te verskaf met die opdrag om dit in die klas te sing. In dié liedjie kom baie verkleinwoorde voor en leerders word gevra om die getal verkleinwoorde in die liedjie te soek en te identifiseer, asook om hul meervoude in die woordeboek na te slaan.

PLA maak ook van die kommunikatiewe benadering gebruik deur 'n teks te verskaf wat aanleerders uit Afrikaans in Engels kan vertaal, asook 'n Afrikaanse teks met spel- en leestekenfoute wat geredigeer kan word.

Die kommunikatiewe benadering is uiters geskik vir aanleerders van ' $n$ taal, maar volgens die konstruktivistiese leerteorie waar die sosiale aard van taal beklemtoon word, kan dit vanweë die leerdergerigtheid daarvan ook baie suksesvol vir huistaalsprekers gebruik word. Leer word volgens die konstruktiviste as 'n sosiale en dus 'n taalgebaseerde aktiwiteit beskou (WKOD 2006). Konstruktivistiese leeromgewings ondersteun die bou van kennis deur sosiale bedinging en is afhanklik van die dialoog tussen leerder en opvoeder en die leerders self. 


\section{Die induktiewe metode as onderrigleeraktiwiteit}

Beyer (2010: 61, 63) onderskei tussen woordeboekonderrig, woordeboekondersteunde taalonderrig en woordeboekgeïntegreerde taalonderrig. Hy wys daarop dat die induktiewe metode baie suksesvol tydens woordeboekgeïntegreerde taalonderrig, oftewel WIT, gebruik kan word. WIT (Beyer 2010: 61) verwys na die bereik van 'n lesdoelwit deur leerdergerigte onderrigleeraktiwiteite. Die gebruik van werkboeke tydens woordeboekgeïntegreerde taalonderrig kan 'n belangrike rol speel in 'n leerdergerigte benadering.

Die induktiewe metode (Meij et al. 1985: 6-7) bestaan daaruit dat die leerlinge aan voldoende voorbeelde van 'n bepaalde taalverskynsel bekend gestel word en deur die onderwyser se leidende vrae self daarin slaag om die betrokke reël, beginsel of verskynsel af te lei of te "ontdek". Taalleeronderrig is dan funksioneel, en nie formeel nie. Sodoende val die klem op taalgebruiksvaardigheid. Dit stel leerders in staat om self afleidings te maak en op dié manier ontdekkings beter te onthou. Daar is heelwat voordele verbonde aan die gebruik van die induktiewe metode vir taalleeronderrig.

Volgens Meij et al. (1985: 6-7) is leerders aktief betrokke by die onderrigproses; dit maak die les interessanter. Dit wat die leerders self ontdek, onthou hulle langer. Hul kennis is dus van 'n blywende aard. Hierdie metode prikkel leerders se denkvermoë en bevorder begrip. Die vlak van aanbieding word sterk beïnvloed deur die bydraes van leerders - dis dus nie te moeilik of te maklik nie. Die onderwyser kom gou agter wat leerders se probleme is en kan dit dan onmiddellik oplos.

\section{Voorstelle vir onderrigleeraktiwiteite in werkboeke}

In hierdie afdeling volg vyf voorbeelde van aktiwiteite volgens die induktiewe metode wat in werkboeke opgeneem kan word. Die onderwerp van die aktiwiteit word telkens verskaf en dan volg die aktiwiteit. Die onderwerpe vorm deel van die KABV vir Afrikaans huistaal vir graad vier. Dit sluit ook aan by Stark (1990) se kontrolelys vir woordeboekvaardighede, soos in die volgende afdeling verwys.

Taalstrukture en -konvensies met die byvoeglike naamwoord: trappe van vergelyking as onderwerp. Lees die onderstaande sin:

Die rooi boek is dikker as die blou boek. Die vergrotende trap van die woord dik is in die sin gebruik. Soek die vergrotende en die oortreffende trap van die volgende woorde in die woordeboek op en skryf dit neer.
(1) lui
(2) blou
(3) bitter 
(4) bleek

(5) loom

Voltooi die volgende sin: Die vergrotende trap van 'n byvoeglike naamwoord word gevorm deur agter die woord te voeg en die oortreffende trap van 'n byvoeglike naamwoord word gevorm deur agter die woord te voeg.

\section{Voorbeeld 1}

Taalstrukture en -konvensies met die selfstandige naamwoord: meervoude as onderwerp.

Soortname het kenmerkend meervoude en dit word in woordeboeke aangedui. Slaan die volgende soortname in die woordeboek na en skryf die meervoud neer.
(1) bal
(2) jas
(3) kam
(4) nar
(5) pet

Voltooi nou die volgende sin: As 'n woord 'n verdubbel die in die meervoud.

klank in die middel het,
(1) beer
(2) haas
(3) blaar
(4) peer
(5) skool

Voltooi nou die volgende sin: As 'n woord verloor hy die tweede in die meervoud.

\section{Voorbeeld 2}

Taalstrukture en -konvensies met die selfstandige naamwoord: verkleinwoorde as onderwerp.

Dit is kenmerkend van soortname om verkleinwoorde te hê en dit word in woordeboeke aangedui. Slaan die volgende soortname in die woordeboek na en skryf die verkleinwoord daarvan neer.
(1) blaf
(2) bek
(3) dop
(4) kas 
Voltooi nou die volgende sin: om 'n verkleinwoord te vorm, sit ons ' $n$ aan die einde van ' $n$ woord by. Indien die woord op _, ${ }_{-}$, en _ eindig en voorafgegaan word deur 'n kort, beklemtoonde vokaal, verdubbel die konsonant.

Slaan die volgende soortname in die woordeboek na en skryf die verkleinwoord daarvan neer.
(1) hond
(2) naald
(3) pad
(4) geut
(5) woord

Voltooi nou die volgende sin: om 'n verkleinwoord te vorm, sit ons ' $n$ aan die einde van ' $n$ woord by wat op ' $n$ _ of _ eindig.

\section{Voorbeeld 3}

Taalstrukture en -konvensies met die bywoord as onderwerp.

Lees die volgende sinne deur en soek die woord in skuinsdruk in die woordeboek op. Watter woordsoort is die woord?

(1) Die motors ry vinnig op die snelweg.

(2) Die atleet oefen hard vir die byeenkoms.

(3) Sy lees gereeld 'n speurverhaal.

(4) Die doel het die doelpaal rakelings gemis.

(5) Die atleet oefen besonder hard vir die byeenkoms.

Voltooi die volgende notas oor die bywoord: indien ' $n$ bywoord ons meer vertel van _ iets gedoen word, noem ons dit ' $n$ bywoord van wyse. Indien ' $n$ bywoord ons meer vertel van __ iets plaasvind, noem ons dit ' $n$ bywoord van plek. Indien ' $n$ bywoord ons meer vertel van iets plaasvind, noem ons dit ' $n$ bywoord van tyd. Indien ' $n$ bywoord ons meer vertel van ' $n$ ander of ' $n$ noem ons dit ' $n$ bywoord van graad.

\section{Voorbeeld 4}

Woordsoorte kan nooit in isolasie getoets word nie, aangesien die rol wat die woord in die sin vervul, die funksie van die woord bepaal. Vergelyk die volgende voorbeelde:

Duik is my gunstelingtydverdryf. (selfstandige naamwoord)

Die dolfyn duik diep in die brander. (werkwoord) 
Bogenoemde is voorbeelde van leerdergerigte aktiwiteite wat in werkboeke opgeneem kan word. Leerders word gelei om self die betrokke reël of verskynsel af te lei. Dit stel leerders in staat om self afleidings te maak en op dié wyse ontdekkings beter te onthou. Dit sluit aan by die konstruktivisme se idee dat leer die bou van kennis behels. Tydens die bou van kennis vind die volgende plaas: redenasie en kritiese denke, probleemoplossing, ontsluiting, verstaan en gebruik van inligting en sorgsame besinning oor ervaring. In bogenoemde gevalle vervul woordeboeke ' $n$ kognitiewe funksie, aangesien data in verband met taalkunde deur die gebruiker nageslaan word.

\section{Ontwikkeling van leerders se vaardighede}

Stark (1990) stel 'n kontrolelys van woordeboekvaardighede voor na 'n evaluering van werkboeke:

- Stel vas watter leksikale item in die leesteks problematies is.

- Soek 'n leksikale item in die makrostruktuur:

1. Bemeester die alfabetiese ordening van lemmas: samestellings, vaste uitdrukkings, kort vorme, frase- en voorsetselwerkwoorde.

2. Soek 'n leksikale item in 'n inskrywing met 'n verskillende lemma: kruisverwysings, redes vir nie-nabye plasing.

3. Soek 'n meerwoordige leksikale item: idiome en vaste uitdrukkings.

4. Kies tussen homonieme, gebruik grammatiese of semantiese inligting.

5. Kies tussen verskillende onderskeidinge van 'n poliseem.

6. Gebruik meer as een lys in die makrostruktuur van 'n woordeboek: voorwerk en aanhangsels rakende afkortings, eiename, lande en nasionaliteite, diername, verwantskapterme, affikse, asook werkwoordverbuigingstabelle.

- Verstaan die beginsels van lemmatisering in woordeboeke: waarom sekere woorde lemmastatus het.

- Soek inligting in die mikrostruktuur

1. Soek inligting oor die spelling of woorde: spelpatrone en verboë vorme, spelling van afkortings, akronieme, spelling van multileksikale items, hoofletters en punktuasie.

2. Soek inligting oor gebruik: styl en register, kollokasies, gebruiksnotas en variëteite.

3. Soek inligting oor die grammatika van woorde: woordsoorte, werkwoordvorme en infleksie, meervoudsvorme, voorsetsels, asook selfstandige naamwoorde wat net in die enkelvoud of meervoud voorkom. 
4. Soek inligting oor die betekenis van woorde: sinonieme, betekenis, kies van die regte definisie, kollokasies, korrekte lemma, polisemiese onderskeidinge, idiomatiese en vaste uitdrukkings.

5. Soek verwante woorde: plek van verwante woorde, sinonieme, paronieme, en antonieme.

6. Gebruik ekwivalente van 'n tweetalige woordeboek.

7. Soek inligting oor die herkoms van woorde.

8. Soek inligting oor die uitspraak van woorde: lettergreepverdeling, klem, uitspraak van homograwe, alternatiewe uitspraak, asook homofone.

9. Kies die geskikte woordeboek op grond van die tipe leksikale item en die inligtingsoort wat verlang word.

10. Weet wat om van woordeboeke te verwag in die algemeen en van elke woordeboek in die besonder.

Bogenoemde lys van vaardighede kan uitgebrei word deur na Afrikaans as huistaal en addisionele taal se doelwitte in die KABV te verwys. Werkboekopstellers moet hulle vergewis van die nasionale kurrikulumverklarings se vereistes en benaderings vir taalleeronderrig en dit moet in werkboeke se inhoude gereflekteer word.

Met die gebruik van werkboeke kan leerders se woordeboekgeletterdheidsvlakke aansienlik verhoog word en opstellers kan van opvoedkundige beginsels kennis neem om die gehalte van werkboeke te verbeter. Die HATS maak van 'n belangrike tegniek in die didaktiese situasie gebruik, naamlik doelwitstelling. Elke aktiwiteit word van 'n uitkoms, d.w.s die doel van 'n aktiwiteit, voorsien, bv. "die aktiwiteite in hierdie afdeling sal jou help om die alfabetiese ordening van trefwoorde en samestellings in die woordeboek te verstaan".

Bloom se taksonomie vir die evaluering van kognitiewe denke (Combrink et al. 1997: 18, 19) is 'n nuttige klassifikasiesisteem vir die beskrywing van die denkvlakke van leerders. Hy identifiseer ses denkvlakke, naamlik kennis, begrip, toepassing, analise, sintese en evaluering. Dié kennisvlakke behoort aandag te geniet in werkboeke om te verseker dat alle denkvlakke en nie net die eerste twee, soos so dikwels voorkom, in werkboeke beslag vind nie. Dit kan verseker dat leerders aan die hoogste vlak van kritiese denke blootgestel word.

\section{Slot}

Dit is van die uiterste belang dat teikengebruikers en die doel van woordeboekwerkboeke gespesifiseer word ten einde hulp en leiding aan ouers en onderwysers te verskaf, aangesien daar groot onkundigheid oor woordeboekwerkboeke 
bestaan. Bewusmaking van die didaktiese waarde van woordeboekwerkboeke is uiters noodsaaklik. Verdere navorsing oor effektiwiteit van werkboeke is nodig waar teoretiese leksikograwe, praktiese leksikograwe en kurrikulumkundiges leksikografiese navorsing in die klaskamer doen.

\section{Bibliografie}

Beyer, H.L. 2010. Kontekstuele bepalers by die beplanning van skoolwoordeboeke. Lexikos 20: 52-72.

Bloom, B.S. 1956. Taxonomy of Educational Objectives, Handbook I: The Cognitive Domain. New York: David McKay.

Chi, Man L.A. 1998. Teaching Dictionary Skills in the Classroom. Fontenelle, Thierry, Philippe Hiligsmann, Archibald Michiels, André Moulin en Siegfried Theissen (Reds.). 1998. ACTES EURALEX'98 PROCEEDINGS, Communications soumises à EURALEX '98 (Huitième Congrès International de Lexicographie) à Liège, Belgique/Papers submitted to the Eighth EURALEX International Congress on Lexicography in Liège, Belgium: 565-577. Leuven: Departemente Engels en Nederlands, Universiteit van Leuven.

Combrink, L., N. Faasen, H. Geyser en A. Kloppers. 1997. Taalkonteks. Kenwyn: Juta.

Departement van Basiese Onderwys. 2011. Nasionale Kurrikulum- en Assesseringsbeleidverklaring Graad R-12. Pretoria: Staatsdrukkery.

Du Plessis, M. 1998. Tweetalige Aanleerderswoordeboek/Bilingual Learner's Dictionary Afrikaans-Engels/ English-Afrikaans. Kaapstad: Pharos Woordeboeke.

Gouws, R.H. 2001. Lexicographic Training: Approaches and Topics. Emejulu, J.D. (Red.). 2001. Éléments de lexicographie gabonaise. Tome I: 58-94. New York: Jimacs-Hillmann.

Gouws, R.H. 2006. Leerdergedrewe leksikografie. Tydskrif vir Taalonderrig 40(1): 72-84.

Gouws, S. en M. Lätti. 2005 Nuwe Woordeboek sonder grense Werkboek Senior fase Graad 7-9. Kaapstad: Maskew Miller Longman.

Gouws, R.H. en D.J. Prinsloo. 2005. Principles and Practice of South African Lexicography. Stellenbosch: SUN PReSS.

Gouws, R.H., M. Stark en L. Gouws. 2004. Nuwe Woordeboek sonder grense. Kaapstad: Maskew Miller Longman.

Gouws, R.H. en S. Tarp. 2008. A New Step Forward for South African Learners' Lexicography: The Oxford Afrikaans-Engels/English-Afrikaans Skoolwoordeboek/School Dictionary. Tydskrif vir Taalonderrig 42(1): 65-79.

Kromhout, J. 2004. Skoolwoordeboek Afrikaans-Engels/School Dictionary English-Afrikaans. Kaapstad: Pharos Woordeboeke.

Louw, P. (Red.). 2007. Oxford Afrikaans-Engels/English-Afrikaans Skoolwoordeboek/School Dictionary. Kaapstad: Oxford University Press Southern Africa.

Luther, J. 2009. HAT Afrikaanse Skoolwoordeboek. Kaapstad: Maskew Miller Longman.

Luther, J. 2010. HAT Aktiwiteite en Speletjies by die Afrikaanse Skoolwoordeboek en Afrikaanse Sakwoordeboek. Kaapstad: Maskew Miller Longman.

Meij, K., T. Kühn en R. Snyman. 1985. Vakdidaktiek: Afrikaans moedertaal in die sekondêre skool. Pretoria: De Jager-HAUM.

Paizee, D. en M.L. Kriel. 2006. Oxford Tweetalige Skoolwoordeboek Werkboek. Kaapstad: Oxford University Press. 
Smith-Müller, W. 2006. Pharos Leerderboek by die Aanleerderswoordeboek. Kaapstad: Pharos Woordeboeke.

Smith-Müller, W. 2007. Pharos Leerderboek by die Skoolwoordeboek. Kaapstad: Pharos Woordeboeke.

Stark, M.P. 1990. Dictionary Workbooks. A Critical Evaluation of Dictionary Workbooks for the Foreign Language Learner. Exeter Linguistic Studies 16. Exeter: University of Exeter Press.

Tarp, S. en R.H. Gouws. 2004. Wie leer wat uit Afrikaanse (aan)leerderwoordeboeke. Tydskrif vir Geesteswetenskappe 44(4): 276-298.

Underhill, A. 2002. Macmillan English Dictionary for Advanced Learners Workbook. Oxford: Macmillan Publishers.

Van der Merwe, M.F. 2013. Kriteria vir woordeboekwerkboeke in Afrikaans. Botha, W., P. Mavoungou en D. Nkomo. 2013. Festschrift RUFUS H. GOUWS: 280-294. Stellenbosch: SUN PReSS.

WKOD Geletterdheid-en syferkundigheidstrategie 2006-2016. 2006. Wes-Kaap Onderwysdepartement. 